\title{
Voltammetry of proteins at liquid-liquid interfaces
}

\section{Damien W. M. Arrigan}

Nanochemistry Research Institute, Department of Chemistry, Curtin University, G.P.O. Box U1987, Perth, Western Australia, Australia 6845. Fax: +61-8-9266-2300; Tel: +618-9266-9735; E-mail: d.arrigan@curtin.edu.au

Abstract: The voltammetric behaviour of proteins at interfaces between two immiscible electrolyte solutions (ITIES) is reviewed. This behaviour is of interest for a number of reasons, including the basis of label-free detection methods and the understanding of the stability of biopharmaceutical and food formulations. The review discusses electrochemical strategies for protein and polypeptide detection, and the mechanisms involved in protein detection at the ITIES. Results obtained by DC and AC voltammetry are included together with data from other complementary techniques.

Highlights: The recent highlights in protein voltammetry at liquid-liquid interfaces are the elucidation of the mechanism of protein detection via an adsorption-induced facilitated ion-transfer (FIT) process and exploitation of this adsorptive property to enable detection of nanomolar protein concentrations. The protein detection mechanism involves complexation by cationic protein, from the aqueous electrolyte phase, of the anion of the organic phase electrolyte. The transfer of the anion across the ITIES is believed to be the charge transfer step detected by voltammetry. Adsorption at the ITIES is important here. Exploitation of this adsorption to preconcentrate protein at the ITIES prior to its detection by voltammetric desorption has enabled detection of proteins at nanomolar concentrations (e.g. lysozyme at $3 \times 10^{-8} \mathrm{~mol} \mathrm{dm}^{-3}$, haemoglobin at $4.8 \times 10^{-8}$ $\mathrm{mol} \mathrm{dm} \mathrm{d}^{-3}$.

\section{Introduction}

Electrochemistry at the interface between two immiscible electrolyte solutions (ITIES) ${ }^{1,2}$ provides a simple strategy to study ion transfer, adsorption, and ion-molecule interactions that occur at or close to the interface under electrochemical control. For many years, the 
structure and properties of these interfaces have been examined ${ }^{3,4}$ and the kinetics and mechanisms ${ }^{4,5}$ of ion transfer reactions have been studied. The information emerging from these studies provides a foundation for applications such as the design of membranes, extraction processes, sensors, molecular separations, drug delivery and various other areas. The focus of this report is to discuss specific features of voltammetric and more general electrochemical behaviour of proteins at the ITIES (and related soft interfaces). Several reviews on broader aspects of electrochemistry at the ITIES have been published recently, to which interested readers are referred. ${ }^{1-6}$ This report is targeted towards analytical ${ }^{7}$ and mechanistic information on protein and polypeptide behaviour at the ITIES.

\section{Principles and Experimental Arrangements}

The key idea for electrochemistry at the ITIES is that ion distributions on both sides of the interface lead to development of an interfacial potential difference, which can be described by a form of the Nernst equation (eq. 1). ${ }^{6}$

$$
\Delta_{\circ}^{\mathrm{w}} \varphi=\Delta_{\circ}^{\mathrm{w}} \varphi_{i}^{0}+\frac{R T}{z_{i} F} \ln \frac{a_{i}(\mathrm{o})}{a_{i}(\mathrm{w})}
$$

where $\Delta_{O}^{W} \varphi$ is the interfacial Galvani potential difference, $\Delta_{O}^{W} \varphi_{i}^{0}$ is the standard transfer potential for ion $\mathrm{i}, z_{\mathrm{i}}$ is the ion charge, $a_{\mathrm{i}}(\mathrm{O})$ and $a_{\mathrm{i}}(\mathrm{W})$ are the ion activities in organic and water phases, respectively, and $R, T$ and $F$ are the gas constant, temperature and Faraday's constant, respectively.

In this equation, the ion activities can be manipulated easily in an experimental system and the chemically-imposed potential difference so generated can be measured with a suitable pair of electrodes and a voltmeter. Such a simple experimental arrangement can employ the aqueous and organic liquid phases, each with low mutual solubility, each containing dissolved electrolytes and with a common ion present in both phases. It is the ratio of concentrations of this common ion across the interfacial boundary which enables the potential difference to be manipulated. Now, rather than measuring the potential difference with the electrodes and the voltmeter, we can instead use an external energy source to impose an applied potential difference between the electrodes. If the applied potential is different from the equilibrium value established by the ion concentration 
ratio, ions must re-distribute cross the ITIES to obey the Nernst equation. We have now moved away from equilibrium, and ion movement across the interface results in an electrical current, which can be measured with a suitable current follower or ammeter. By imposition of different applied potential differences and measurement of the resultant current, we can construct a plot of current versus applied potential, which of course yields a voltammogram. Such experiments are routinely enacted throughout the world with electrochemical instruments commonly referred to as potentiostats, by which the applied potential difference is systematically varied whilst measuring the resultant current and with, nowadays, simultaneous plotting of the current-applied potential difference curve (voltammogram) on a computer screen. Just as voltammetry is applied routinely at solid|liquid interfaces to study redox behaviour of solutes dissolved in the liquid phase, or to study electrochemical transformations of the solid phase itself, so too can voltammetry (and its various experimental variations) be applied at the ITIES to measure currents associated with ion transfers and related reactions.

The use of voltammetry to study charge transfer reactions at the ITIES has encompassed simple ion-transfer, facilitated ion-transfer and electron transfer reactions, all of which are relevant to protein electrochemistry at the ITIES. Simple ion transfer refers to the process of transferring an ion with some hydrophobic character from the aqueous phase, in which it is dissolved, to the organic phase by virtue of the applied potential. Figure 1 shows a typical cyclic voltammogram for the transfer of $\mathrm{Cs}^{+}$cations from the aqueous phase to the organic phase (on the forward scan or half-cycle) and the reverse transfer from organic to aqueous phases on the reverse half-cycle. ${ }^{8}$ The mid-point potential $\left(E_{m}\right)$ or formal potential $\left(\mathrm{E}^{\mathrm{o},}\right)$ can be obtained for the ion-transfer process $\left(\mathrm{E}_{\mathrm{m}}=\left(\mathrm{E}_{\mathrm{p}, \mathrm{f}}+\mathrm{E}_{\mathrm{p}, \mathrm{r}}\right)\right.$ / 2, where $E_{p}, f$ and $E_{p}$,r are the peak potentials for the forward and reverse scans, respectively), just as for an electron transfer reaction at a solid electrode, and is related to the ions' Gibbs energy of transfer. ${ }^{1}$

Facilitated ion transfer (FIT) occurs when an ionophore is added (usually) to the organic phase to aid the transfer of hydrophilic ions from the aqueous phase into the organic phase. The typical example that can be mentioned here is the facilitated ion-transfers of alkali metal cations by crown ether derivatives. ${ }^{9}$ Shao et al. ${ }^{10}$ put forward various mechanisms for these facilitated ion transfers, involving complexation in the organic phase, in the aqueous phase or at the interface. Finally, electron transfer reactions across the ITIES can be studied when suitable redox couples are dissolved in both phases. Under 
an applied potential difference, these redox-active species react, with transfer of electrons across the interface. ${ }^{1}$ When the redox species are appropriately chosen, so that the oxidation or reduction products of both couples are insoluble in the adjoining phase, then ion-transfer does not accompany the electron transfer process and the latter can be studied without complications.

The experimental arrangement for electrochemistry at the ITIES ${ }^{11}$ typically involves an aqueous phase containing hydrophilic electrolyte species and an organic phase comprising a solvent that has low solubility in water combined with a reasonable dielectric constant, so that salts of hydrophobic cations and anions can dissolve and dissociate in the solvent. Typical solvents employed in the organic phase are nitrobenzene (NB), 1,2-dichloroethane (1,2-DCE) or 1,6-dichlorohexane (1,6-DCH). The choice of electrolyte species in each phase is important. As with many electrochemical experiments, the presence of the electrolyte is in a supporting role and is normally chosen to be inert, serving as the background electrolyte. If any of the electrolyte ions transfer across the ITIES then the current produced masks the current due to transfer of specific species under study and limits the available potential window under which experiments can be implemented. For this reason, hydrophobic cations, such as alkylammonium cations like bis(triphenylphosphoranylidene)ammonium, and hydrophobic anions, such as tetraphenylborate derivatives, are employed. Generally, a potential window in the region of $1 \mathrm{~V}$ can be achieved with correct choice of electrolytes, where the potential window refers to the range of potential within the limits set by the transfer of background electrolyte ions. Within this potential window, ion transfer processes can be studied by voltammetry.

The geometric size of the ITIES influences the electrochemical behaviour observed. At millimetre or centimetre-sized ITIES, mass transport of ions by diffusion is planar, leading to time-dependent current-potential curves (such as shown in Figure 1) at typically-used potential scan rates. Hence, peak-shaped voltammograms are obtained. Such ITIES experiments are run with four electrode cells, comprising of a counter electrode in each phase, employed to measure the current, and a reference electrode in each phase to enable control of the interfacial potential difference. However, in the 1980s, miniaturised ITIES were introduced by Girault and co-workers, ${ }^{10,12-16}$ first in the form of ITIES formed at the mouths of micropipettes and then in the form of ITIES formed at single or arrays of microholes drilled into polymer sheets and other materials. ${ }^{17,}{ }^{18}$ The 
formation and properties of these $\mu$ ITIES, and subsequently introduced nanoITIES, ${ }^{19} 20,21$ will not be discussed here other than when they have been employed for studies of protein electrochemistry. A detailed recent review by Shao and colleagues ${ }^{22}$ should be consulted for information on the development of micro/nanoITIES, as well as an additional comprehensive account of the detection of biological molecules (large and small) at such miniaturised ITIES. ${ }^{23}$ Importantly, these miniaturised ITIES can be operated in twoelectrode mode, simply because the currents are so low that no polarisation of the reference electrodes occurs and they maintain their chemically-induced potentials.

The final experimental feature of the ITIES that should be mentioned is its mechanical stability. Obviously a liquid-liquid interface has many advantages for electrochemical studies, including the ready formation of new and reproducible interfaces. However for studies related to sensor and analytical applications, a more mechanically rigid interfacial arrangement can be useful. As a result, gelled phases ${ }^{24-26}$ are sometimes employed, usually with gellification of the organic phase by addition of poly(vinyl chloride) (PVC), but aqueous phases can also be gelled using a suitable polymer.

\section{Protein voltammetry at the ITIES.}

The electrochemistry of proteins at solid electrodes (or, more correctly, at solid-liquid interfaces) has a rich history and forms much of modern bioelectrochemistry. ${ }^{27,} 28$ Important outcomes from such studies have been in understanding and applications of enzyme-based electrode systems for bioelectrochemistry and biosensing, such as the commercially successful glucose biosensors, ${ }^{29}, 30$ but also prospective biofuel cell applications. ${ }^{31}$ However, the electrochemical behaviour of proteins at the ITIES is less well-developed and has received much less attention. Nevertheless, the electrochemistry of proteins at these soft interfaces offers great scope for uncovering of new information about protein behaviour and stability, including the impact of orientation, folding/unfolding and interactions (with proteins or with small molecules and ions) on that behaviour. The nature of protein electrochemistry at the ITIES readily lends itself to universal protein detection strategies, as the forcing of ion-transfer reactions can be applied to all proteins under appropriate (i.e. protein-specific) conditions. Furthermore, the behaviour of proteins at the ITIES can also be important in understanding and controlling protein stability in biopharmaceutical formulations ${ }^{32}$ and in foodstuffs. ${ }^{33}$ Consequently, the fundamental chemistry involved in a protein reaction at an ITIES offers 
scope for impact outside the research laboratory.

\subsection{Early studies}

Early studies of the behaviour of proteins at the ITIES were reported by Vanysek and colleagues, ${ }^{34-36}$ in which proteins were examined within a programme to assess the behaviour of biological molecules in general. In these studies, the main findings were that proteins such as ovalbumin, colicine $E_{3}$, and bovine serum albumin (BSA) form adsorbed layers at the ITIES. These layers were studied by cyclic voltammetry and impedance methods and revealed that simple ion transfer reactions were inhibited (e.g. transfer of $\mathrm{Cs}^{+}$across the ITIES between water and NB), ${ }^{35}$ as shown in Fig 2. Here, the experimental arrangement was that of a large interface (i.e. millimetre or centimetre in scale) set up in a glass cell containing two counter electrode and two reference electrodes. The broadening of the voltammogram in the presence of the protein layer, compared to in the absence of the protein, indicates the retardation of the ion transfer reaction by the adsorbed layer. These studies by CV of ion transfer inhibition were followed up with impedimetric studies, which showed changes in interfacial capacitance as a function of protein concentration, BSA in this case, ${ }^{35,36}$ and providing an indicator of the works to emerge two decades later.

Importantly, in these early studies, the voltammetry presented did not indicate any ion transfer processes of the proteins themselves, although some changes in the width of the available potential window were observed. ${ }^{35}$ That is, although neither protein transfer nor protein-facilitated ion transfer was reported, it appears that the electrolyte ions did interact in some way with the adsorbed protein film.

\subsection{Polypeptides at the ITIES}

\subsubsection{Protamine.}

The recent surge of interest in voltammetry at the ITIES of polypeptides and proteins commenced with the report by Amemiya et al. ${ }^{37}$ of the behaviour of protamine at the $\mu$ ITIES. Protamine is a polypeptide (molecular mass in the range of 4000-4250 Daltons) comprised of 30 amino acids, of which ca. two-thirds are arginine. The ionisable R-group on arginine, which contains a guanidinium functional group, means that it is highlypositively charged at physiological $\mathrm{pH}$. In this study, micropipette-based ITIES were 
employed in which the inner solution (inside the pipette) was the organic phase. Different organic phase solvents were evaluated, namely NB, 1,2-DCE and 1,6-DCH. Figure 3 shows a CV for protamine at the water-NB microinterface. Here, the forward current is steady-state in behaviour and the reverse current is peak-shaped. These indicate that diffusion of protamine from the aqueous phase to the interface is the controlling process on the forward sweep, and diffusion of protamine in the organic phase to the interface is the controlling process on the reverse sweep. At the water-NB microinterface, the process is a simple ion-transfer process. It was noted that as the dielectric constant of the organic phase solvent was lowered, the presence of a pre-peak in the voltammogram became more prominent. Voltammetric pre-peaks are usually indicative of the adsorption of the product of an electrochemical reaction on the electrified interface. For example, at the water-1,2DCH microinterface, the pre-peak possessed a charge consistent with the adsorption of ca. $2 \times 10^{-10} \mathrm{~mol} \mathrm{~cm}^{-2}$ of protamine at the interface, assuming a molecular ionised charge $z_{i}$ of +20 for protamine. This surface coverage represents more than a monolayer coverage for a molecule of this size. Although these pre-peaks are indicative of the adsorption of a product of the electrochemical reaction on the interface, it generally is not possible to unequivocally state which product and on which side of the interface the product adsorbs, from purely electrochemical studies. Subsequent experiments employed chronoamperometry to probe the adsorption/transfer process of protamine at the microinterface. ${ }^{38}$ Both the molecular charge $\left(z_{i}=20 \pm 1\right)$ of the polypeptide and its diffusion coefficient $\left((1.2 \pm 0.1) \times 10^{-6} \mathrm{~cm}^{2} \mathrm{~s}^{-1}\right)$ were determined from current-time transients, based on simple ion-transfer reactions even if complicated by an adsorption process.

Facilitated ion transfer studies of protamine at a $\mu$ ITIES between water and 1,2-DCE were reported by Amemiya and colleagues. ${ }^{39}$ For these studies, the reagent dinonylnaphthalenesulfonate (DNNS) was added to the organic phase (as the tetradodecylammonium salt) to facilitate the transfer of protamine via complex formation. DNNS has been reported previously for use in potentiometric membrane electrodes for protamine. ${ }^{40}$ Figure 4 illustrates the scheme of reactions occurring at the ITIES for this facilitated ion transfer process. Indeed, it was shown that the presence of DNNS promotes the complete transfer of protamine to the organic phase, with complexation occurring at the interface. By appropriate analysis of voltammograms and chronoamperograms, the diffusion coefficient $\left(1.0( \pm 0.3) \times 10^{-6} \mathrm{~cm}^{2} \mathrm{~s}^{-1}\right)$ and molecular charge number $\left(z_{i}\right)$ of 
transferred protamine (21 \pm 1$)$ were determined. Moreover, the reaction stoichiometry (s) was determined to be $20.0 \pm 0.4$, indicating that the $c a$. +20 charge of each protamine molecule was balanced by the binding of 20 DNNS molecules. The overall reaction was determined to be

$$
\text { sDNSS-(1,2-DCE) }+\operatorname{protamine}^{Z^{+}}{ }_{(\mathrm{aq})}===\text { protamine-DNNS }_{\mathrm{s}(\mathrm{complex})(1,2-\mathrm{DCE})}
$$

with the hydrophilic protamine stabilised in the organic phase by surface-active DNNS. The overall reaction was broken down into steps involving DNNS adsorption at the interface, reaction of aqueous phase protamine with adsorbed DNNS, and transfer of the adsorbed complex from the interface into the organic phase.

The behaviour of protamine at a large-sized ITIES, (i.e. $1.2 \mathrm{~mm}$ radius), in the presence of organic phase DNNS (as the tetrapentylammonium salt) was reported by Osakai's group. ${ }^{41}$ This was part of a larger study (to be discussed in a later section, below) but the data for protamine voltammetry at this larger water-1,2-DCE interface did indicate that protamine diffused in the organic phase, consistent with its interfacial transfer and it not being retained at the interface.

Trojanek et al. ${ }^{42}$ reported a comprehensive study of counter anion binding to protamine at the water - 1,2-DCE ITIES. The objective here was to clarify whether organic phase electrolyte anions were involved in binding to protamine at the interface, in the absence of surfactant anions such as those used by the Amemiya ${ }^{39}$ and Osakai ${ }^{41}$ groups. Together with voltammetry at the ITIES, Trojanek et al. ${ }^{42}$ used quasi-elastic light scattering and complementary data from conductometric titrations. The anions studied were tetraphenylborate (TPB), tetrakis(4-chlorophenyl)borate (TPBCl) and tetrakis[3,5bis(trifluoromethyl)phenyl]borate (TFPB). Cyclic voltammetry at the ITIES revealed peaks on the forward and reverse scans that shifted to lower potentials as the anions of the organic phase electrolyte became more hydrophobic, evidently due to the formation of protamine-anion ion pairs and to formation of ion-pairs of differing stabilities. The QELS data, used to construct interfacial tension curves as a function of the applied potential difference, indicated adsorption of protamine-organic anion ion-pairs at the ITIES. The location of these adsorbed ion-pairs on the aqueous side of the ITIES, i.e. no interfacial transfer of the protamine, as well as possible involvement of aqueous anions in the process, was discussed. The surface coverage values of the adsorbed complex were assessed and interpreted using the Frumkin isotherm, with repulsive interactions between adsorbed species. Monolayer surface coverages ( $c$. $8 \times 10^{-11} \mathrm{~mol} \mathrm{~cm}^{-2}$ ) were determined 
for protamine in the potential region below that required for interfacial charge transfer; there was no appearance of pre-peaks as reported by Amemiya et al. ${ }^{37}$ and as have been seen for studies with larger proteins.

\subsubsection{Insulin.}

Another polypeptide that has received some attention is insulin, which regulates carbohydrate metabolism in mammals. Studies by Thomsen et al. ${ }^{43}$ and Kivlehan et al. ${ }^{44}$ were carried out for different goals, namely the understanding of adsorption kinetics of protein pharmaceuticals at interfaces and the development of bioanalytical methods, respectively. In diabetes, formulated insulin products are used as a treatment, and the ability to detect insulin at low concentrations may provide a viable strategy for analysis of clinical samples.

Thomsen et al. ${ }^{43}$ used alternating current (AC) voltammetry, which involves application of a sinusoidal signal to the electrochemical cell on top of the applied DC potential difference. In this case, the sinusoidal signal was of $5 \mathrm{mV}$ amplitude with a frequency of $6 \mathrm{~Hz}$. This method enables the construction of capacitance - voltage curves from which information about the potential of zero charge (PZC) and qualitative indication of adsorption can be obtained. Evidence was determined for the adsorption of insulin at the water-1,2-DCE interface for insulin concentrations as low as $0.1 \mu \mathrm{M}$. Although detailed structural analysis was not available, the data presented show that both insulin concentration and the applied potential difference influence the adsorption profile.

The study by Kivlehan et al. $^{44}$ employed predominantly cyclic voltammetry and was aimed towards an analytical detection method for insulin. It was found, employing a large water - 1,2-DCE ITIES, that insulin could be detected in the micromolar concentration range, and that the peak on the forward CV scan had a pre-peak that was linearly dependent on the scan rate. This linear dependence of current on the scan rate indicates an adsorbed layer at the interface and its presence as a pre-peak is associated with the adsorption of a reaction product, similar to that reported by Amemiya's group ${ }^{37}$ for protamine at certain water-organic interfaces. Furthermore, Kivlehan et al. ${ }^{44}$ reported that the main forward charge transfer and back-transfer peaks associated with insulin shifted in potential when the organic phase electrolyte anion was made more hydrophobic, signifying the formation of an insulin-organic anion complex; this ion-pairing was 
supported by the fact that insulin was detected only when present in the aqueous phase at a pH lower than it's isoelectric point (pI), 5.5. Below the pI, insulin is cationic, while above its pI, it is anionic. In the latter state, it does not seem to interact with the cations available on the organic side of the interface and hence no detection current is registered, whereas in the former state (cationic), it appears to have an interaction with the anions of the organic phase electrolyte which enables its detection. It was also reported that maximal adsorption occurred at $\mathrm{pH}$ values close to the isoelectric point, as detected by disturbance of the transfer of tetraethylammonium cations, where insulin has lowest solubility.

\subsubsection{Other polypeptides.}

More recently, interest in polypeptides and their interactions with lipids, especially lipid bilayer membranes, has stimulated studies of polypeptide and lipid interactions at the ITIES. For many years, the formation and stability of lipid monolayers at the ITIES has been examined, ${ }^{45}$ noting that the lipid monolayers are formed because of the tendency of the lipid to assemble at the ITIES with its polar head facing the aqueous phase and its non-polar tail directed into the organic phase.

Girault’s group have studied angiotensin III (AngIII), ${ }^{46}$ Leu-enkephalin (LeuEnk), ${ }^{46}$ and melittin $^{47}$ at the ITIES and lipid-modified ITIES. AngIII and LeuEnk interact with receptors in cell membranes while melittin is an anti-microbial peptide which interacts directly with lipid membranes, causing disruption and cell death. In all cases, voltammetry at the ITIES revealed transfer of the peptide in the presence of a lipid monolayer at the ITIES.

The AngIII and LeuEnk study ${ }^{46}$ employed a liquid-liquid interface formed in a glass cell where the interfacial area was $1.53 \mathrm{~cm}^{2}$. At $\mathrm{pH} 5$, that of the aqueous phase employed, AngIII was cationic and enabled its detection both in the absence and presence of lipid. Sweep rate studies yielded a diffusion-controlled transfer of AngIII across the ITIES in the absence of lipid. The impact of the lipid monolayer was the appearance of a voltammetric pre-peak, consistent with the adsorption of a AngIII-lipid complex at the interface. However, LeuEnk was neutral at the experimental conditions employed and was detected only upon complexation with the lithium cation of the aqueous phase electrolyte. Confirmation of the formation of peptide-lipid species was obtained by an 
online mass spectrometry method.

Melittin, a well-known anti-microbial peptide, was shown to transfer across the ITIES from an aqueous phase of $\mathrm{pH} \mathrm{3}$, in this case based on an aqueous droplet suspended on a platinum electrode and surrounded with the organic phase. ${ }^{47}$ In the presence of a lipid monolayer, additional voltammetric peaks were evident, indicating the utility of voltammetry at the ITIES as a screening method for antimicrobial peptides. The data presented here were consistent with melittin disruption of the lipidic monolayer.

\subsection{Proteins at the ITIES}

A number of studies of protein behaviour at the ITIES have now appeared, in which the experimental conditions range from a millimetre-scale interface, to an array of microinterfaces, with liquid organic phase or gelled organic phase, in the absence and presence of surfactant added to the organic phase, and using direct current voltammetry (e.g. CV) or alternating current methods (such as AC voltammetry or electrochemical impedance spectroscopy).

\subsubsection{Protein adsorption at the ITIES.}

The adsorption of proteins at the ITIES has been studied by AC methods such as electrochemical impedance spectrometry and AC voltammetry. These techniques are especially useful for assessing the capacitance of the interface in the presence and absence $^{48}$ of adsorbing species. Proteins studied in these ways include glucose oxidase, lysozyme, protamine, haemoglobin.

Georganopolou et al. ${ }^{49}$ examined the adsorption of glucose oxidase (GOx) at the ITIES and compared results to those at the air-water interface. At the ITIES, capacitance-voltage curves were established by use of EIS at different DC applied potentials and evaluation of the capacitance from fitting of data to a simple equivalent circuit model. Shifts in the potential of zero charge (PZC), obtained from the minima of capacitance-voltage curves, are used to indicate the presence of adsorption. For GOx, the PZC was shifted to lower potentials. There was evidence for the interaction of the adsorbed GOx with the cation of the organic phase electrolyte, which suggests electrostatic interactions since the experiments was performed with GOx present initially in the $\mathrm{pH} 7$ aqueous buffered electrolyte solution. At this $\mathrm{pH}$ GOx is anionic (pI ca. 4.4). Enzyme monolayers were 
formed at the ITIES, but the thickness changed with enzyme concentration, suggesting some orientational rearrangements of the protein within the monolayer. Bilayers were suggested to form at concentrations above $1 \mu \mathrm{M}$ and in higher ionic strength aqueous media. It was noted that GOx behaved as a simple organic dielectric material, blocking the interface and leading to changes in capacitance and in the PZC upon adsorption. It was speculated that hydrophobic parts of the enzyme might penetrate into the organic phase, allowing some interaction with the ions of the organic electrolyte.

Studies of haemoglobin (Hb) by Herzog et al. ${ }^{50}$ using AC voltammetry revealed that this protein adsorbed at the ITIES when present in an acidic aqueous phase. Under these conditions Hb was cationic, and the shift in PZC to lower potentials was consistent with adsorption of cationic particles to the interface, as seen by Jensen et al. for nanoparticle adsorption. $^{51}$ Jensen and colleagues also used this method to study hen-egg-whilelysozyme (HEWL) adsorption at the ITIES, ${ }^{52}$ as will be discussed below. However, it is to be noted that shifts of PZC in the negative direction have also been reported for negatively-charged proteins (GOx, as mentioned above) and polypeptides (insulin). Hence, the shift in PZC is more a qualitative indication of adsorption, noting that a protein may have regions of positive and negative charge distributed across its surface despite its net charge being positive or negative, and the shift in PZC may be indicative of which portion of the macromolecule is interacting with the interface.

More recently, Jensen and colleagues have examined by modelling and experiment the formation of protein dielectric layers at the ITIES and the impact of this on the regulation of protein charge in such adsorbed layers. ${ }^{53}$ A model for interfacial capacitance that incorporates protein adsorption was developed and used to predict and interpret experimental data. The formation of a protein dielectric layer at the interface was recognised to lead to possible formation of a layer with a lower relative permittivity than the aqueous medium. Taken into account with the fact that the charge of an ampholyte is not considered constant but is influenced by the local environment, it was concluded that charge regulation lead to the protein net charge being lower in the adsorbed layer than in bulk aqueous solution. The model developed could explain the changes in capacitance observed for some proteins that were less structurally stable, termed soft proteins.

Note that these AC techniques are applied at potentials where no interfacial charge transfer occurs. This means that surface coverages discussed (e.g. assumed monolayers in model development) are low compared to those experimentally observed upon interfacial 
charge transfer, which can often lead to multi-layers of proteins.

\subsubsection{Ion transfer voltammetry involving proteins at the ITIES.}

The voltammetric behaviour of cytochrome c (Cyt c) at the water - 1,2-DCE interface was examined by Shinshi et al. ${ }^{54,55}$ as part of a study on a number of proteins. Since cyt c is coloured, containing the iron haem group, it could be detected visually and spectroscopically. Using cyclic voltammetry, these researchers obtained well-defined voltammetric charge transfer peaks. Importantly, no transfer of coloured material to the organic phase was observed at this ITIES. As a result, it was concluded that the charge transfer process was the movement of organic phase anion, tetraphenylborate in this case, across the interface to associate with the cyt c on the aqueous side of the interface. The peak on the reverse half-cycle of the CVs was also seen to be a sharp bell-shaped curve, which is a characteristic indication of an adsorption/desorption process.

The voltammetric behaviour of haemoglobin at the ITIES was examined by Herzog et $a l{ }^{56}$ These studies revealed a charge transfer across the water - 1,2-DCE ITIES (geometric area $1.16 \mathrm{~cm}^{2}$ ) that was diffusion-controlled but that resulted in a build-up of a precipitate at the interface upon repeated potential cycling. Figure 5 shows typical CVs for $\mathrm{Hb}$ carried out immediately and upon waiting for a set time before implementation of the scan. The forward and reverse peaks here varied with the square root of the sweep rate, indicative of a diffusion-controlled current. Moreover, no transfer peaks were observed if the experiment was carried out in a phosphate buffered saline solution at $\mathrm{pH}$ 7, which is above the pI of the protein. Analogous to the above discussion for insulin, $\mathrm{Hb}$ was detected only when present in its cationic state, in which it is proposed to be able to interact at the ITIES with the anions of the organic phase electrolyte. This interaction was further confirmed by varying the organic phase electrolyte anion. As the anion was made more hydrophobic, the transfer peak potential shifted, indicating the involvement of a Hbanion complex in the detection process at the ITIES.

Additional studies were performed to assess whether any interaction with organic phase cations was possible, using aqueous phase solutions with a $\mathrm{pH}$ suitable for anionic $\mathrm{Hb}$ (i.e. above the pI of the protein). However, no charge transfer peaks were observed. Single sweep $\mathrm{CV}$ at $\mathrm{pH}$ values where $\mathrm{Hb}$ was cationic produced voltammetric peak charges consistent with adsorption of more than a monolayer of $\mathrm{Hb}$ at the ITIES, ${ }^{50}$ 
assuming that a single anion from the organic phase interacted with each positive charge on the $\mathrm{Hb}$ macromolecule. Complementary studies by acoustic sensor methods ${ }^{57}$ revealed that when adsorbed on a gold surface, $\mathrm{Hb}$ does indeed interact with the typical anions of the organic electrolyte, namely the tetraphenylborate derivatives TFPB, TPBCl and TPB.

A similar set of studies to that for $\mathrm{Hb}$ was reported by Scanlon et al. ${ }^{58}$ for the behaviour of HEWL at the ITIES, again a water - 1,2-DCE interface. Figure 6 shows a typical CV for HEWL at the ITIES. This CV displays features consistent with adsorption of a reaction product at the ITIES, (pre-peak in the figure) as well as diffusion-controlled ion transfer currents. Moreover, by variation of the $\mathrm{pH}$ of the aqueous phase in which the HEWL was dissolved, changes occurred in both the peak shape and in the current associated with the peaks. Notably, the current due to the diffusion-controlled ion-transfer peak on the forward CV sweep (at $c a .0 .38 \mathrm{~V}$ in Fig 6) was seen to vary in agreement with the acid-base titration curve of the protein. Note that for HEWL, since its pI value is high (ca. 11.2) it can be detected across a wide $\mathrm{pH}$ range since it is cationic from alkaline conditions right through to the acidic conditions employed. At pH 12 aqueous phase electrolyte, no currents associated with ion transfer involving the protein were detected. Conversely, greater current was obtained at lower $\mathrm{pH}$ values of aqueous phase electrolyte, because of the higher charge on the cationic protein at lower $\mathrm{pH}$. As identified previously for protamine, insulin and haemoglobin at the ITIES, changing the organic phase electrolyte anion, for increasingly more hydrophobic species, namely TPB, TPBCl and TFPB, resulted in a shift of the peak potentials to higher values (in this case). This, again, indicates an interaction between the cationic protein and the anionic species of the organic phase. On the basis of the characteristics determined, a mechanism including protein adsorption, facilitated anion transfer and protein re-orientation and/or denaturation steps was put forward.

\subsubsection{Mechanism of protein electrochemistry at the ITIES.}

Clearly, a number of reports cite the formation at the interface of cationic protein-organic anion complexes as being of vital importance in the electrochemistry of proteins at the ITIES. If such is the case, then transport of the organic phase anion, within the organic phase, should be significant and testable. Based on previous reports of the ability of micropipette-based $\mu$ ITIES to be employed to identify which species is crossing the interface, based on voltammetric shapes, ${ }^{59}$ Scanlon et al. undertook a series of 
investigations of protein electrochemistry at arrays of $\mu$ ITIES. ${ }^{60}$ Here, the organic phase was placed within the pores of a microporous silicon membrane. The walls of these micropores restrict diffusion within the pores to a linear regime, which in turn will control the voltammetric shape. The idea here is that species transferring from the aqueous phase to the organic phase will undergo radial diffusion and produce a steadystate voltammogram, whereas species transferring from the organic phase to the aqueous phase will undergo linear diffusion and result in a peak-shaped voltammogram, and these voltammograms should be time-independent and time-dependent, respectively. Figure 7 shows background-subtracted CVs for HEWL at the $\mu$ ITIES array together with plots of forward and reverse current versus square root of the sweep rate. The linear nature of the forward current plot is indicative of linear diffusion control of the charge transfer process, which supports the idea that the limiting process is the diffusion of organic phase anions within the confines of the micropores. Similar data were reported for insulin. ${ }^{60}$

Hartvig et al. ${ }^{52}$ employed an online mass spectrometry method to detect protein-anion complexes formed at the interface. The biphasic electrospray ionisation - mass spectrometry (BESI-MS) method enables the detection and characterisation of species formed in interfacial reactions. However, it requires use of MS-compatible electrolytes and, as a result, Hartvig et al. first investigated the electrochemical behaviour of HEWL at the water - 1,2-DCE ITIES using an acetic acid aqueous electrolyte at $\mathrm{pH} 2.9$, close to the acidic conditions identified as optimal by Scanlon et al., but using neither LiCl nor $\mathrm{HCl}$, which are not MS-compatible. Similar electrochemical data were obtained, validating the use of the acetic acid electrolyte. Most interestingly, the BESI-MS experiments revealed for the first time the formation of HEWL-TPBCl complexes. Figure 8 shows spectra for reaction products formed under different conditions of imposed potential difference. Here, chemistry was employed to impose the potential difference (equation (1)) by changing the interfacial ratio of concentrations of a common ion, in this case $\mathrm{TPBCl}^{-}$. It was determined that at negative imposed potential difference and at open circuit potential, protein - anion complexes were present, but the imposition of a positive potential difference yielded a greater intensity of the MS signal for these complexes. This was related to the adsorption of HEWL at the interface: lower potential differences cause lower amounts of the protein to adsorb and hence is less available for complexation with the anion in the organic phase, whereas higher potential differences caused adsorption of greater amounts of protein (in agreement with capacitance data) and hence more intense 
MS signals for the protein-anion complexes. Although protein-anion complexes have been detected by MS, the complexes have protein:anion ratios of 1:3 at most, and hence are a long way from the 1:17 ratio required for complete charge neutralisation of the protein by organic phase anions, assuming that the protein's charge in aqueous bulk solution conditions is retained in its interfacial affiliation. Charge regulation of proteins, in particular HEWL, at the ITIES ${ }^{53}$ supports the observation of lower protein-anion ratios by BESI-MS.

As discussed above, haemoglobin interaction with the organic phase anions has been confirmed by an online acoustic sensor device, although this does not present information for a liquid-liquid interfacial reaction, simply the reaction of immobilised $\mathrm{Hb}$ with the anions, all in contact with an aqueous phase. ${ }^{57}$

It has been proposed that the detection mechanism for proteins at the ITIES is based on protein adsorption and formation of protein-hydrophobic anion complexes, by location of the hydrophobic anion within hydrophobic pockets of the protein. It seems logical, then, that if the protein is unfolded or broken-up in some manner so that those hydrophobic pockets are destroyed, then the protein detection signal at the ITIES should be different. Herzog et al. investigated this scenario, by denaturing proteins with urea ${ }^{61}$ and by enzymatic digestion. ${ }^{62}$ Indeed, it was found that the signals for these denatured or digested proteins were different from those of the native proteins. However, it must be borne in mind that when examining the electrochemistry of a protein in an acidic aqueous phase in contact with an organic phase, there is considerable scope for at least partial denaturation in the acidic phase and in contact with the interface, irrespective of any intentional denaturation using regular denaturants such as urea. Despite that, protein unfolding curves were constructed by examining the electrochemistry of protein at ITIES following exposure of the protein to different concentrations of urea. ${ }^{63}$

\subsubsection{Protein detection at the $\mu$ ITIES.}

The development of miniaturised liquid-liquid interface systems, ${ }^{22}$ based on either micro(nano)pipettes or porous membranes, offers a numbers of advantages to electrochemistry at the ITIES. For example, decreased ohmic (IR) drop, lower capacitance and higher mass transfer rates were attractive to charge transfer kinetic studies. These also offer benefit to analytical (concentration detection) studies by way of 
lower background signals, hence perhaps lower detection limits, and higher mass transport rates, leading to greater sensitivity for mass transfer-controlled electrochemical reactions. Most studies to-date of proteins at the $\mu$ ITIES have been associated with qualitative investigation of the mechanism of reaction and the assessment of analytical utility, rather than determination of charge transfer kinetics. Hence, this section provides an overview only of analytical sensitivity studies; mechanistic aspects were addressed above.

Detection of haemoglobin, ${ }^{50,56} \mathrm{HEWL}^{58}$ and insulin ${ }^{44}$ studies at millimetre-sized liquidliquid interfaces have generally enabled the detection by CV of low-micromolar concentrations of these analytes. Our recently introduced silicon microporous membranes, for formation of $\mu$ ITIES arrays, ${ }^{17,18}$ were used for studies of HEWL and insulin detection by voltammetry, with the lowest concentrations detected being $0.5 \mu \mathrm{M}$ and $1 \mu \mathrm{M}$, respectively, following background subtraction. ${ }^{60}$ Gelled organic phases were employed here, which provide mechanical stability, enabling use of an experimental "device" comprising of the membrane defining the $\mu$ ITIES array, the gelled organic phase, the reference solution and reference electrode for the organic side of the interface. Background subtraction involves subtracting a "blank" voltammogram (i.e. one run for electrolyte solutions only, without the target ion) from a voltammogram run on electrolytes containing the target (analyte) ion (e.g. Figure 1). This strategy is useful in removing the background current associated with charging of the interface and even removal of ion-transfer processes associated with non-inert electrolytes. However, it should be kept in mind that, in situations where target ion (analyte) adsorption occurs, the background processes are not necessarily identical in the absence and presence of the target ion. Hence background-subtraction may be a source of experimental artefacts.

A recent study ${ }^{64}$ of the behaviour of myoglobin at a $\mu$ ITIES array indicated a similar detection capability as seen for HEWL and insulin, namely the achievement of $1 \mu \mathrm{M}$ detection. Additionally, it was found that a single CV cycle resulted in the adsorption and desorption of an interfacial layer of the protein consistent with a coverage of 10-50 pmol $\mathrm{cm}^{-2}$, assuming that the protein was fully protonated when in aqueous acidic ( $\left.\mathrm{pH} 2\right)$ solution. This level of surface coverage equates to ca. three monolayers of the protein, similar to that reported for a single CV cycle of haemoglobin at a liquid-liquid ITIES. ${ }^{50}$ Hence, it appears that miniaturisation of the ITIES to the microscale has not resulted in any benefit in analytical detection capability for proteins. This may be a kinetic limitation 
in the charge-transfer process, as discussed recently by Amemiya et al. ${ }^{65}$ in relation to the detection of heparin (a mixture of sulfonated carbohydrates). Nevertheless, the use of a $\mu$ ITIES array in the format of a gelled organic phase in contact with the liquid aqueous (sample) phase does offer the benefits of stabilised interfaces that are more mechanically robust, that can be regenerated in situ and onto which protein species can be intentionally adsorbed and desorbed by choice of suitable applied potentials.

Examination of this potential-controlled adsorption and desorption process for analytical detection purposes was undertaken using HEWL as a model protein. ${ }^{66}$ It was found that at positive potentials, HEWL adsorption can be controlled to enable build-up of a multilayer of protein at the water-organogel microinterface array. By use of voltammetric desorption, scanning to a lower potential, a voltammetric peak was obtained that was dependent on both the protein concentration and the adsorption time. Figure 9 shows typical stripping voltammograms for the detection of HEWL following adsorptive accumulation at the aqueous-organogel microinterface array for different times. Such an analytical approach is generally termed adsorptive stripping voltammetry (AdSV), in which the analyte is detected by stripping away from the electrified interface following its previous adsorptive accumulation there. This prior adsorptive accumulation serves to enhance the local concentration at the interface, which is the concentration detected by the voltammetric step. Although this strategy is widely used at mercury electrodes for the determination of metal ions as complexes with specific chelating agents, the detection of HEWL in this way was the first example of this strategy at an electrified aqueous-organic interface for protein detection. The calculated limit of detection (LOD) was $30 \mathrm{nM}$ (for a 300 seconds adsorption time), representing an improvement of more than an order of magnitude on the use of CV at the $\mu$ ITIES array. ${ }^{60}$ Interestingly, multilayer assemblies were determined to be present at the interface, equivalent to a surface coverage of 550 pmol $\mathrm{cm}^{-2}$ (and considering that a monolayer of HEWL is ca. $13 \mathrm{pmol} \mathrm{cm}^{-2}$ ). More recently, the AdSV approach has been applied to the detection of haemoglobin, ${ }^{67}$ in which case the calculated LOD was $48 \mathrm{nM}$, for a $60 \mathrm{~s}$ adsorptive preconcentration period, as well as to the detection of $\mathrm{HEWL}^{68}$ at a water-ionic liquid microinterface array. ${ }^{69}$

Achieving nanomolar LODs for model protein analytes is a valuable step toward the eventual realisation of direct label-free determination of proteins in biological matrices.

\subsubsection{Surfactants and the voltammetry of proteins}


The impact of surfactants on protein electrochemistry at ITIES has been examined by a number of groups. At the ITIES, natural (e.g. lipids) and synthetic surfactants have been investigated and in the latter case have been the basis of "electrochemical instability". 70, 71 In the presence of proteins, surfactants have been exploited for the opportunity to assemble into reversed micelles in the organic phase, and into which the protein might transfer and reside, thus providing it with a more hospitable environment than transfer into a pure organic phase. Although reverse-micelle extraction of proteins has been used in protein science and technology for many years, ${ }^{72,}{ }^{73}$ Karyakin and co-workers ${ }^{74-76}$ were the first to study this from an electrochemical perspective, seeking to achieve electrochemical formation of reverse micelles and the electrochemical extraction of proteins into these. Vagin et al. ${ }^{74}$ employed the sodium salt of AOT (Aerosol-OT, bis(2ethylhexyl)sulfosuccinate) in the organic phase of a traditional four-electrode ITIES cell. However, the interface was not polarisable, which was attributed to the spontaneous formation of reverse micelles and transfer of aqueous phase electrolyte into the organic phase. Further studies ${ }^{75,76}$ utilising a solid carbon electrode coated with a thin film of organic phase, octane in this case, were successful in achieving protein transfer into the organic phase in the presence of reverse micelles.

Osakai and colleagues employed $\mathrm{AOT}^{41,54,55}$ and $\mathrm{DNNS}^{41}$ in studies of reverse micelle extraction of proteins. Importantly, both surfactants were employed as salts of a hydrophobic cation. In experiments with organic phase AOT, the electrochemical control of reverse micelle formation was presented, and in the presence of aqueous phase cyt c, protein transfer was evident by the appearance of a new set of voltammetric peaks at lower potentials than found for AOT or protein alone. The organic phase solution in the vicinity of the interface was observed to take on a red colour following application of a sufficient potential to drive charge transfer, in contrast to the case in absence of the surfactant. This is qualitative indication that the protein transfers into the organic phase, by interaction with the AOT molecules and reverse micelles. DNNS was also able to facilitate the transfer of cyt c to the organic phase although there was less diffusional behaviour associated with this system, indicating that transfer and adsorption at the ITIES was facilitated. In addition to AOT and DNNS, Osakai et al. ${ }^{41}$ also examined the electrochemistry of proteins in the presence of $\operatorname{bis}(2,2,3,3,4,4,5,5,6,6,7,7-$ dodecafluoroheptylsulfosuccinate (BDFHS) and bis(2-ethylhexyl)phosphate (BEHP). The potential at the foot of the protein transfer voltammetric wave was seen to vary with 
protein and with surfactant, perhaps offering some opportunity for selective transfer/adsorption of proteins in a mixture. It seems possible that careful choice of surfactant for specific protein applications may allow selectivity to be achieved. In fact, the detection of serum albumen protein in urine samples was recently reported, ${ }^{77}$ in which the detection process was facilitated by the surfactant DNNS in the organic phase. Here, the aqueous - 1,2-DCE interface was formed in a flow cell system, in which the fragile liquid-liquid interface was stabilised within a porous polytetrafluoroethylene tubing. Urine analysis necessitated sample dialysis prior to electrochemical measurements, to remove small ions that may interfere with the protein transfer/adsorption detection process. Hence, it seems that prospects for protein determinations in biological fluids are now advancing, noting that the achieved LOD was $1.2 \mu \mathrm{M}$ and that an AdSV strategy was not employed, so that there is scope for lowering of the LOD.

From an analytical (detection) perspective, the impact of added surfactant, in this case the sodium salt of AOT, on analytical performance characteristics, specifically the sensitivity was examined. ${ }^{78}$ The experimental arrangement here was a gelled $\mu$ ITIES array formed at the mouths of micropores within a silicon membrane. It was found that while the analytical signal (current) and determined surface coverages were greater in the presence of organic phase AOT (six-fold and 17-fold, respectively, relative to measurements in the absence of surfactant), the background charging current was also larger, probably a result of interface instability. As a result, this surfactant-modified $\mu$ ITIES array system is not immediately amenable to routine analytical detection studies. Note that addition of the sodium salt of AOT to the gelled organic phase provided a substantially wider electrochemical window than use of AOT as a salt with triphenylphosphoranylidene. Nevertheless, as stated, the background current was larger, which may be a consequence of sodium ions spontaneously transferring from the gelled organic phase to the aqueous phase.

\section{Conclusions and challenges.}

There has been much interest in the electrochemistry of proteins at liquid-liquid interfaces in the past decade or so. This interest has been driven from both a fundamental understanding and the possibility of applications of new electrochemical behaviour in protein detection assays and devices. The behaviour of proteins at millimetre-scale and microscale ITIES, at aqueous - gelled organic phase interfaces, in the absence and in the 
presence of synthetic surfactants has been examined. Much progress has been made in understanding protein behaviour at the ITIES, with results now indicating that proteins adsorb at the interface and, when present in an aqueous phase with a $\mathrm{pH}$ lower than the $\mathrm{pI}$ of the protein, serve as receptors for the transfer of organic phase anions. The roles of aqueous phase $\mathrm{pH}$, protein charge and organic phase anion is crucial, as it has been found that proteins in aqueous phases above the protein pI are not detected, indicating that the cations employed in the organic phase are not amenable to complexation with the proteins. Notably, on-line biphasic electrospray mass spectrometry has identified the presence of protein-anion complexes, and these are present in greater concentrations when a positive interfacial potential difference is applied.

One of the great putative benefits of protein electrochemistry at the ITIES is the prospect for label-free detection and applications in bioanalytical measurements such as disease diagnostics. Such applications require extremely low detection limits. As mentioned, the presence of protein adsorption in the detection mechanisms has offered scope for decreases in the detection limits. By employing potential-controlled adsorption at the ITIES, enhancement of detection capability has been achieved, with detection limits in the low nanomolar concentration region now obtained on a routine basis. This compares to concentrations of low micromolar which can be detected without use of the adsorptive behaviour of protein at these interfaces. As a result, this exotic form of electrochemistry is now beginning to look like it can deliver on some of the opportunities offered by bioanalytical applications.

However, substantial challenges remain. Notable amongst these are the further elucidation of the detection mechanisms and the nature of intermediate species (proteinanion complexes, for example) formed. Indeed, examination of protein layers at electrified interfaces using structural methods would be enlightening. Additionally, the issue of protein selectivity needs to be examined as at present although some differences in protein detection can be achieved, it is not enough to resolve proteins in mixtures and allow determination of, for example, a single type of protein in a complex mixture unless extensive sample pretreatment steps (e.g. dialysis) are implemented. 


\section{Figures}

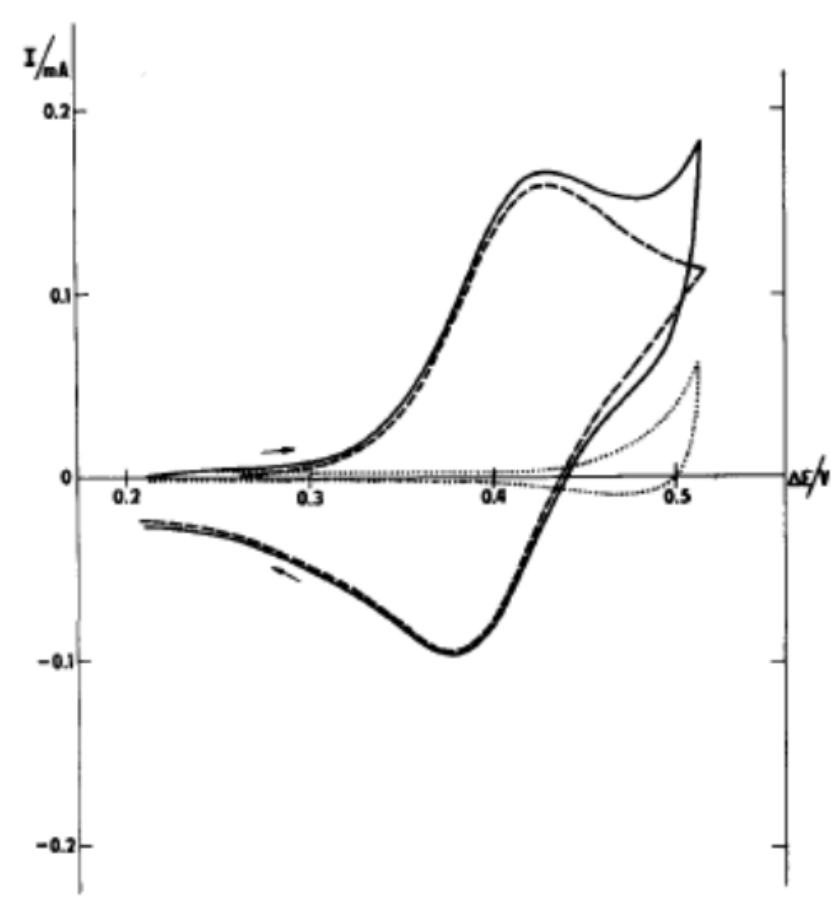

Figure 1. $\mathrm{CV}$ of $\mathrm{Cs}^{+}(1 \mathrm{mM})$ transfer across the aqueous - nitrobenzene interface (solid line). The dotted line is the CV of the cell with background electrolytes only, and the dashed line is the $\mathrm{CV}$ of $\mathrm{Cs}^{+}$transfer corrected for the background electrolyte current. Aqueous phase is $0.05 \mathrm{M} \mathrm{LiCl}$, organic phase is $0.05 \mathrm{M}$ tetrabutylammonium tetraphenylborate. Reprinted from J. Electroanal. Chem., Vol. 100, Pages 841-852, Z. Samec, V. Mareček, J. Weber, Charge transfer between two immiscible electrolyte solutions: Part II. The investigation of $\mathrm{Cs}^{+}$ion transfer across the nitrobenzene/water interface by cyclic voltammetry with IR drop compensation, Copyright (1979), with permission from Elsevier. 


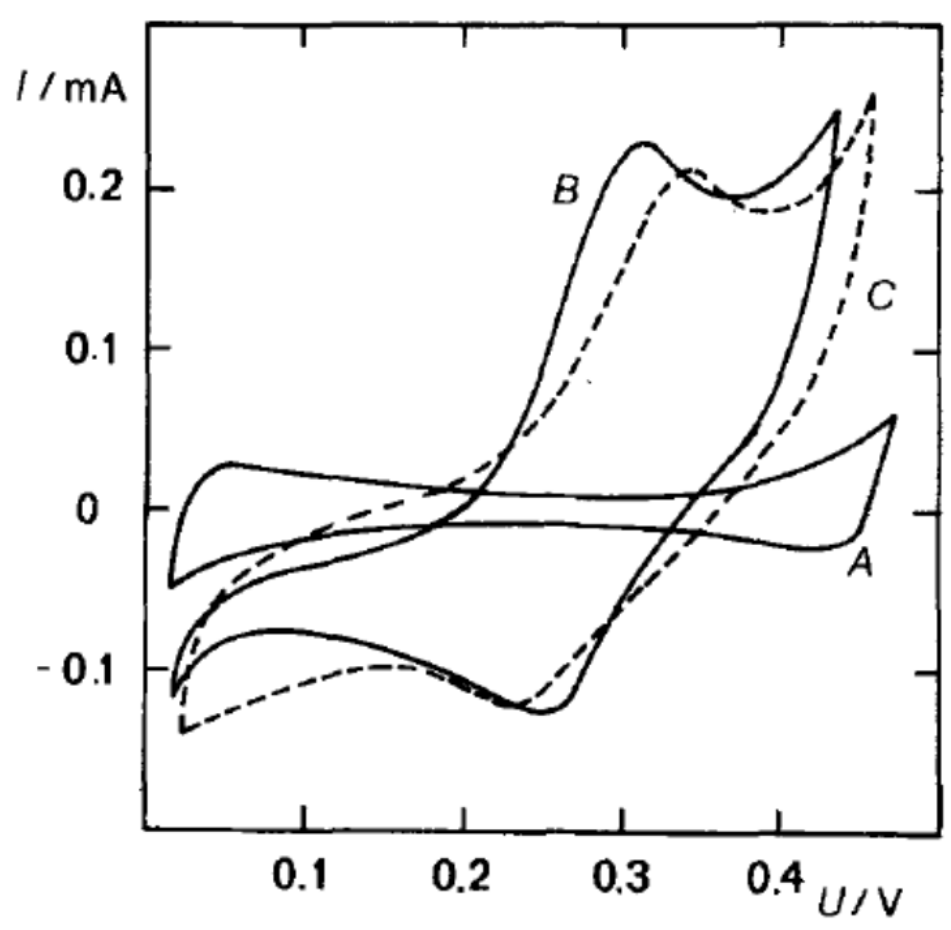

Figure 2. $\mathrm{CV}$ of $\mathrm{Cs}^{+}(0.92 \mathrm{mM})$ transfer across the aqueous - nitrobenzene interface in the absence (B) and presence (C) of ovalbumin $\left(4 \mu \mathrm{g} \mathrm{ml}^{-1}\right)$. Background electrolytes: aqueous 10 $\mathrm{mM} \mathrm{LiCl}$; organic $25 \mathrm{mM}$ tetrabutylammonium tetraphenylborate. Curve (A) is that of the background electolytes only. Reprinted with permission from P. Vanysek, J. D. Reid, M.A. Craven and R. P. Buck, Properties of the interface between two immiscible electrolytes in the presence of proteins, J. Electrochem. Soc., 1984, 131, 1788-1791. Copyright 1984, The Electrochemical Society. 


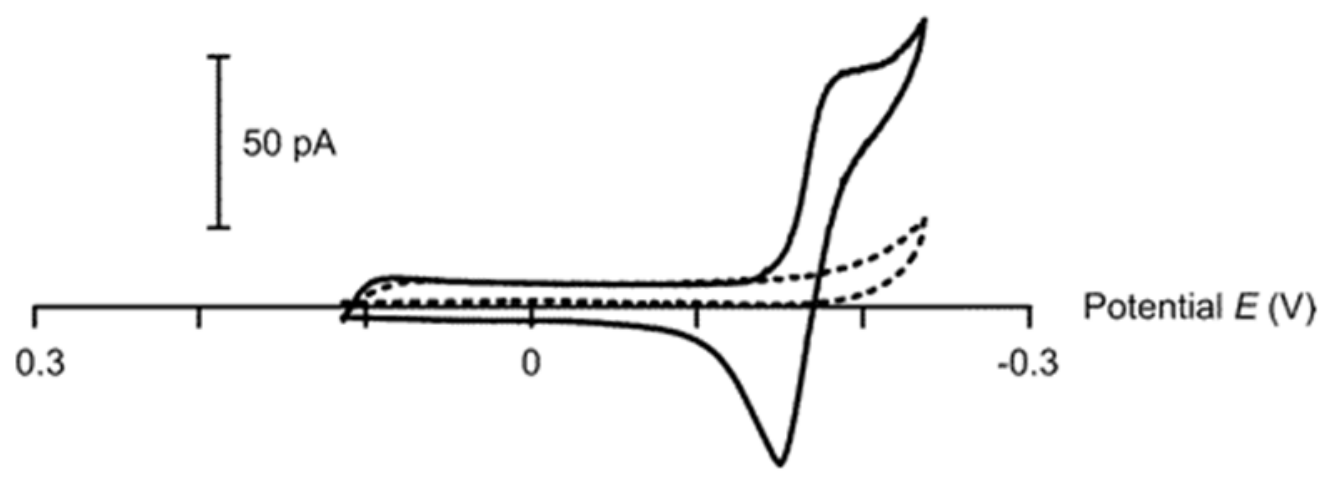

Figure 3. $\mathrm{CV}$ of $12 \mu \mathrm{M}$ protamine at an aqueous - nitrobenzene microinterface formed at a micropipette tip (radius $4.8 \mu \mathrm{m}$ ). Reprinted with permission from S. Amemiya, X. T. Yang and T. L. Wazenegger, Voltammetry of the Phase Transfer of Polypeptide Protamines across Polarized Liquid/Liquid Interfaces, J. Am. Chem. Soc., 2003, 125, 11832-11833. Copyright (2003) American Chemical Society. 


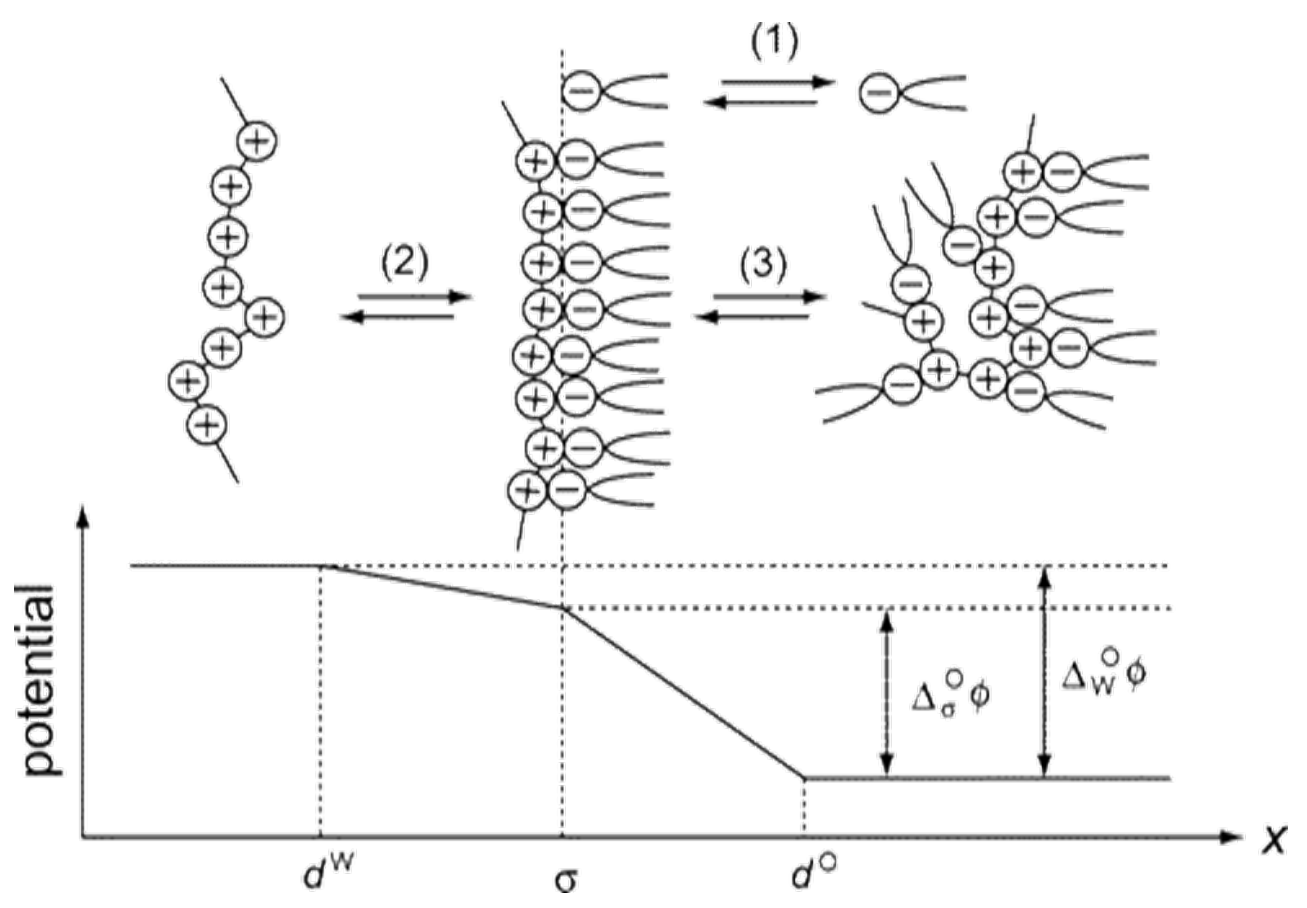

Figure 4. Scheme for the facilitated ion-transfer reaction of protamine at the ITIES (top), based on (1) DNNS adsorption, (2) interfacial complexation between protamine in the aqueous phase and DNNS at the adsorption plane, and (3) complex adsorption. The adsorption plane is at $x=\sigma$. There are pure water and 1,2-DCE phases at $x<d^{\mathrm{W}}$ and $x>d^{\mathrm{O}}$, respectively. Reprinted with permission from Y. Yuan and S. Amemiya, Facilitated Protamine Transfer at Polarized Water/1,2-Dichloroethane Interfaces Studied by Cyclic Voltammetry and Chronoamperometry at Micropipet Electrodes, Anal. Chem., 2004, 76, 6877-6886. Copyright (2004) American Chemical Society. 


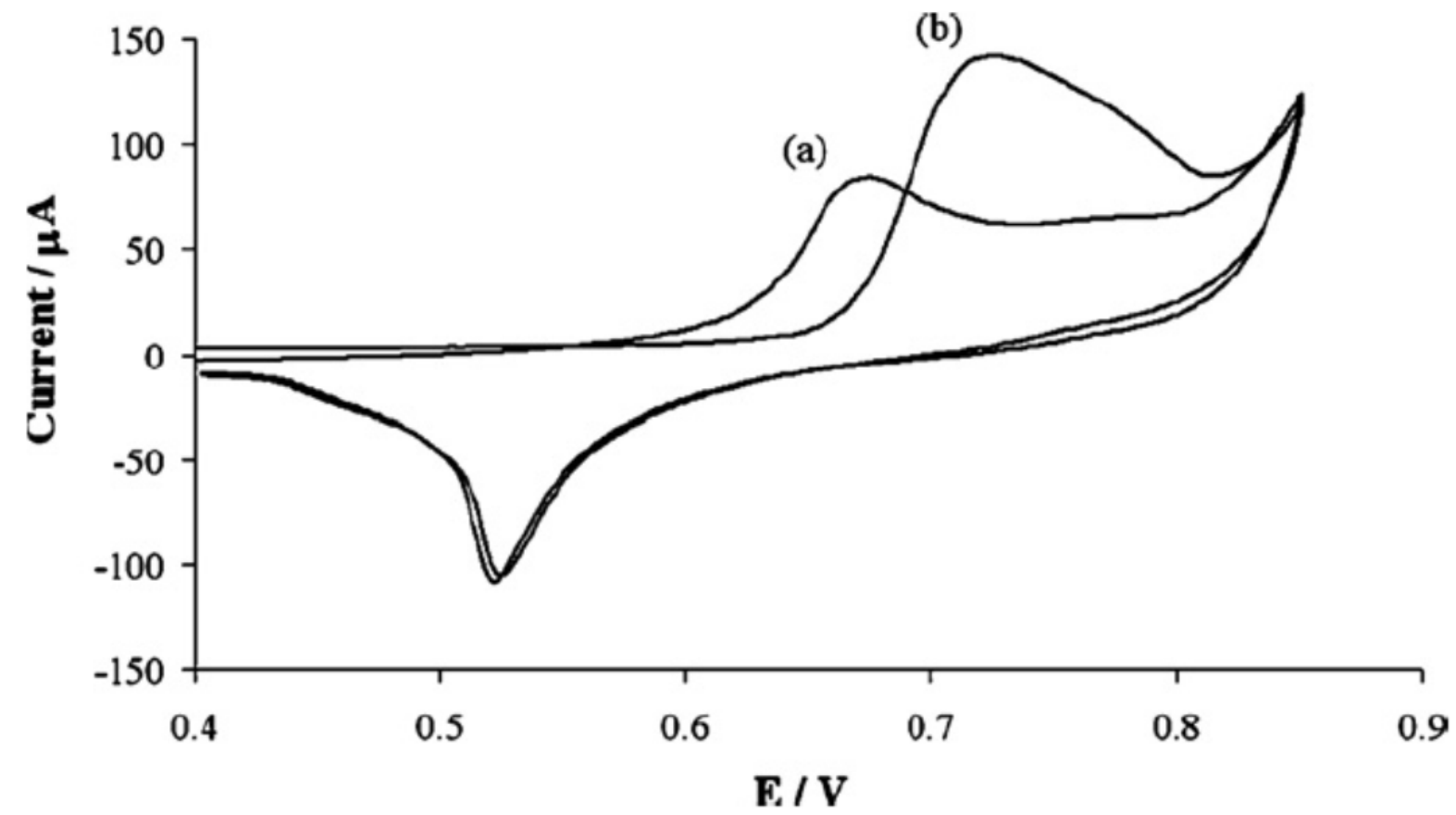

Figure 5. CV of haemoglobin $(15.25 \mu \mathrm{M})$ at the aqueous - 1,2-dichloroethane interface. (a) is the CV taken upon immediate set-up of the cell and (b) was taken 45 min after set-up. Aqueous phase $10 \mathrm{mM} \mathrm{HCl}$, organic phase $10 \mathrm{mM}$ BTPPA TPBCl. Reprinted from Electrochim. Acta, Vol. 53, Pages 7204-7209, G. Herzog, V. Kam, D.W.M. Arrigan, Electrochemical behaviour of haemoglobin at the liquid/liquid interface, Copyright (2008), with permission from Elsevier. 


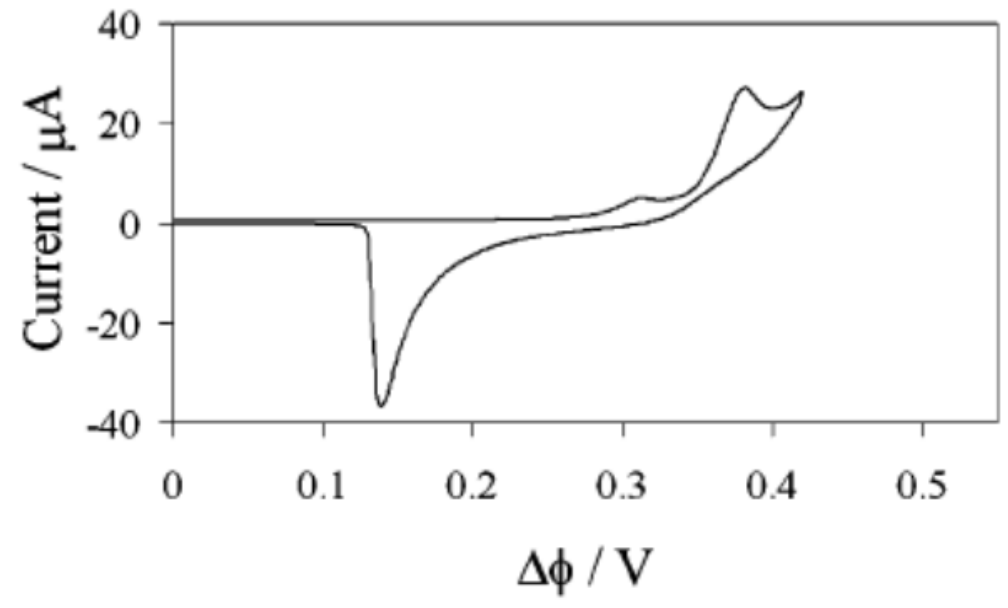

Figure 6. CV of hen egg white lysozyme $(25 \mu \mathrm{M})$ at the aqueous - 1,2-dichloroethane interface. Aqueous phase $10 \mathrm{mM} \mathrm{HCl}$, organic phase $10 \mathrm{mM}$ BTPPA TPBCl. From M.D. Scanlon, E. Jennings, D.W.M. Arrigan, Electrochemistry of hen egg white lysozyme at water|1,2-dichloroethane interfaces, Phys. Chem. Chem. Phys., 2009, 11, 2272-2280. RSC Copyright. 


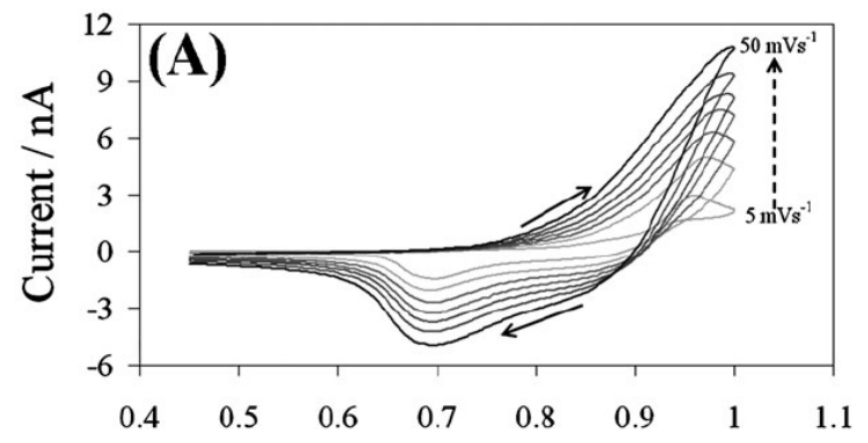

Potential / V

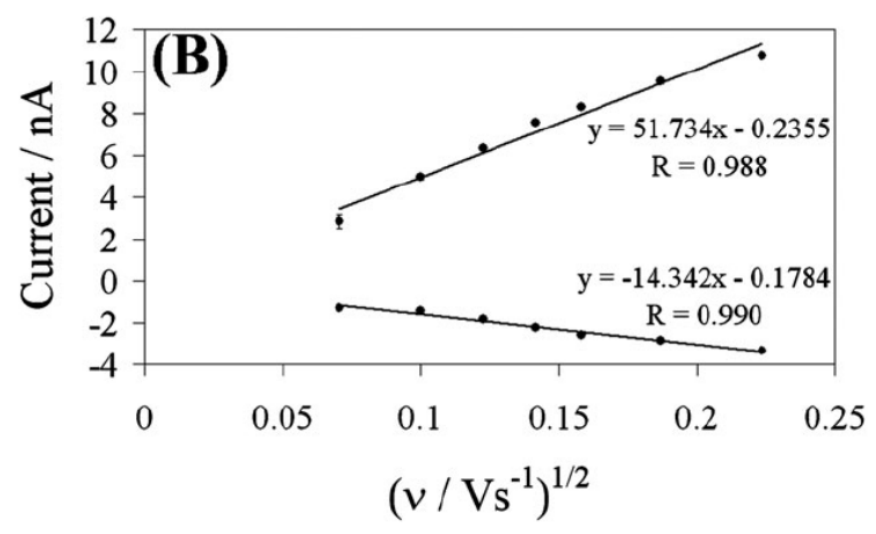

Figure 7. (A) CVs of $10 \mu \mathrm{M}$ hen egg white lysozyme at the microinterface array between aqueous $10 \mathrm{mM} \mathrm{HCl}$ and gelled 1,6-dichlorohexane containing $10 \mathrm{mM} \mathrm{BTPPA} \mathrm{TPBCl.} \mathrm{CVs}$ recorded at different scan rates $\left(5,10,15,25,35,50 \mathrm{mV} \mathrm{s}^{-1}\right)$ are displayed. (B) plots of peak current versus square root of the voltammetric sweep rate. From M.D. Scanlon, J. Strutwolf, D.W.M. Arrigan, Voltammetric behaviour of biological macromolecules at arrays of aqueous|organogel micro-interfaces, Phys. Chem. Chem. Phys., 2010, 12, 10040-10047. RSC Copyright. 

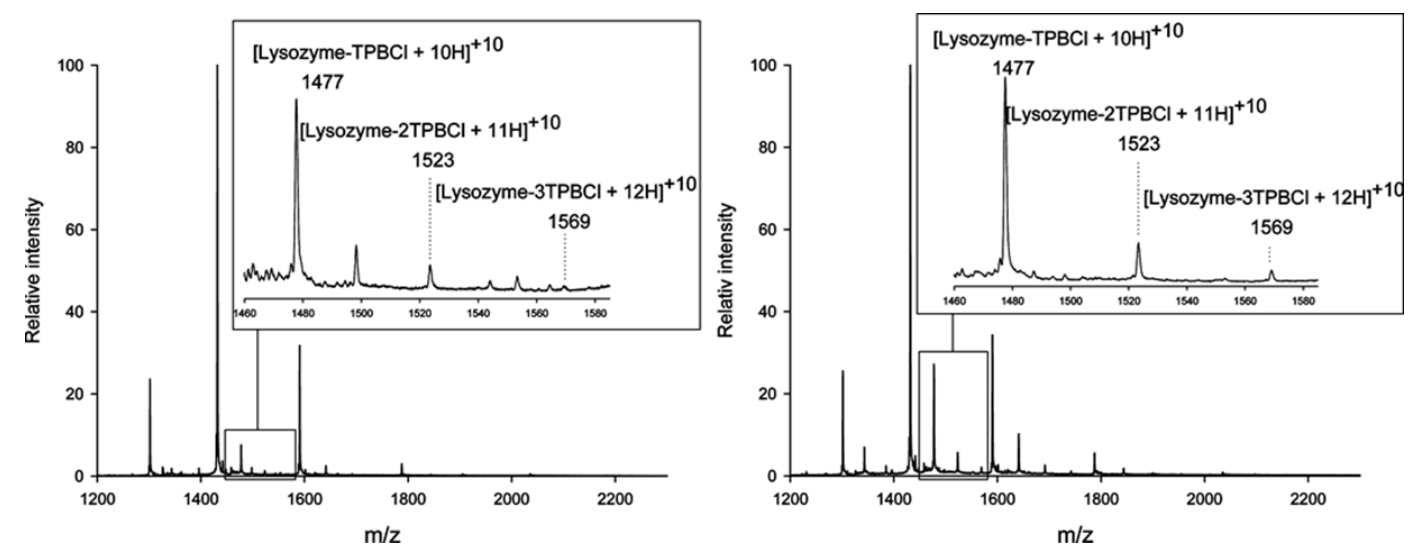

Figure 8. Biphasic Electrospray ionisation - Mass Spectrometry (BESI-MS) at the chemically-polarised ITIES. Left: an imposed negative potential difference between water and 1,2-DCE. Aqueous phase: $100 \mu \mathrm{M}$ Lysozyme and $10 \mu \mathrm{M}$ BTPPACl in $0.5 \%$ (v/v) acetic acid. Organic phase: $10 \mu \mathrm{M}$ BTPPATPBCl in 1,2-DCE. 1:1, 1:2 and 1:3 complexes are observed at lower relative amounts than at open circuit potential. Right: an imposed positive potential difference between water and 1,2-DCE. Aqueous phase: $100 \mu \mathrm{M}$ Lysozyme and 10 $\mu \mathrm{M} \mathrm{KTPBCl}$ in $0.5 \%(\mathrm{v} / \mathrm{v})$ acetic acid. Organic phase: $10 \mu \mathrm{M} \mathrm{BTPPATPBCl}$ in 1,2-DCE. $1: 1,1: 2$, and $1: 3$ complexes are observed at higher relative amounts than at open circuit potential. Reprinted with permission from R.A. Hartvig, M.A. Méndez, M. van de Weert, L. Jorgensen, J. Østergaard, H.H. Girault and H. Jensen, Interfacial Complexes between a Protein and Lipophilic Ions at an Oil-Water Interface, Anal. Chem., 2010, 82, 7699-7705. Copyright (2010) American Chemical Society. 


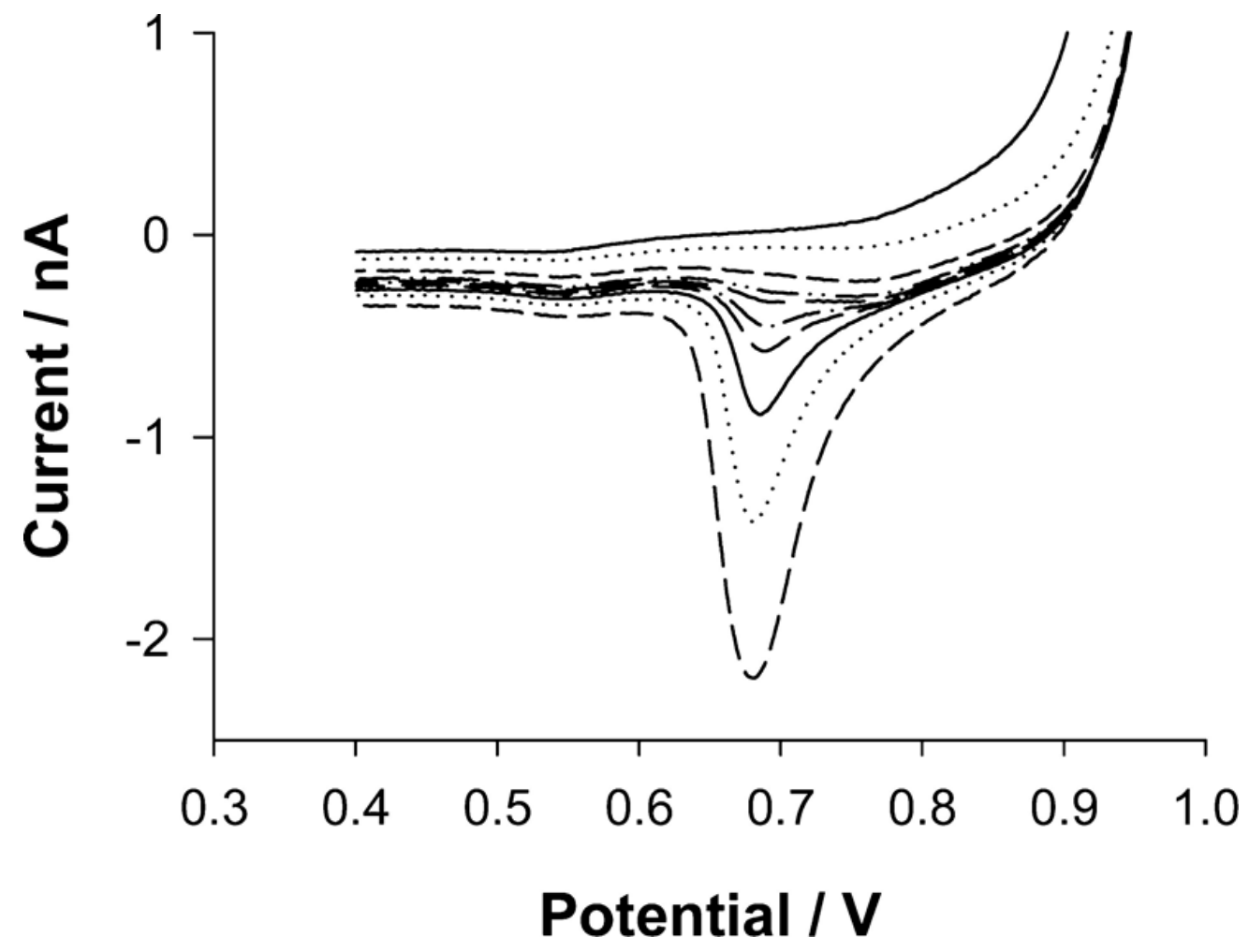

Figure 9. Adsorptive stripping voltammetry of hen egg white lysozyme $(0.1 \mu \mathrm{M})$ following different adsorptive preconcentration times: from $0 \mathrm{~s}(-)$ to $1800 \mathrm{~s} \mathrm{(--)} \mathrm{via} \mathrm{times} \mathrm{of} \mathrm{5,} \mathrm{60,}$ 150, 180, 240, 300, 480, and 900 s. Reprinted with permission from E. Alvarez de Eulate and D.W.M. Arrigan, Adsorptive Stripping Voltammetry of Hen-Egg-White-Lysozyme via Adsorption-Desorption at an Array of Liquid-Liquid Microinterfaces, Anal. Chem., 2012, 84, 2505-2511. Copyright (2012) American Chemical Society. 


\section{References}

1. H. H. Girault, in Electroanalytical Chemistry, A Series of Advances, Vol 23, eds. A. J. Bard and C. G. Zoski, 2010, pp. 1-104.

2. Á. Molina, C. Serna, J. A. Ortuño and E. Torralba, Annual Reports Progress Chemistry, Section C: Physical Chemistry, 2012, 108, 126-176.

3. R. A. W. Dryfe, in Advances in Chemical Physics, Vol 141, 2009, vol. 141, pp. 153-215.

4. Z. Samec, Electrochim. Acta, 2012, 84, 21-28.

5. Z. Samec, in Liquid-liquid interfaces: Theory and methods, ed. A. G. Volkov, Deamer, D. W. , CRC Press, Boca Raton, 1996, p. 155.

6. Z. Samec, Pure Appl. Chem., 2004, 76, 2147-2180.

7. D. W. M. Arrigan, Analytical Letters, 2008, 41, 3233-3252.

8. Z. Samec, V. Marecek and J. Weber, J. Electroanal. Chem., 1979, 100, 841-852.

9. D. Homolka, L. Q. Hung, A. Hofmanova, M. W. Khalil, J. Koryta, V. Marecek, Z. Samec, S. K. Sen and P. Vanysek, Anal. Chem., 1980, 52, 1606-1610.

10. Y. Shao, M. D. Osborne and H. H. Girault, J. Electroanal. Chem., 1991, 318, 101-109.

11. P. Vanysek and L. B. Ramirez, J. Chil. Chem. Soc., 2008, 53, 1455-1463.

12. G. Taylor and H. H. J. Girault, J. Electroanal. Chem., 1986, 208, 179-183.

13. A. A. Stewart, G. Taylor, H. H. Girault and J. McAleer, J. Electroanal. Chem., 1990, 296, 491-515.

14. H. J. Lee, P. D. Beattie, B. J. Seddon, M. D. Osborne and H. H. Girault, J. Electroanal. Chem., 1997, 440, 73-82.

15. M. C. Osborne, Y. Shao, C. M. Pereira and H. H. Girault, J. Electroanal. Chem., 1994, 364, 155-161.

16. M. D. Osborne, Y. Shao, C. M. Pereira and H. H. Girault, J. Electroanal. Chem., 1994, 371, 291-291.

17. R. Zazpe, C. Hibert, J. O'Brien, Y. H. Lanyon and D. W. M. Arrigan, Lab on a Chip, 2007, 7, 1732-1737.

18. J. Strutwolf, M. D. Scanlon and D. W. M. Arrigan, Analyst, 2009, 134, 148-158.

19. C. X. Cai, Y. H. Tong and M. V. Mirkin, J. Phys. Chem. B, 2004, 108, 17872-17878. 
20. B. Kralj and R. A. W. Dryfe, Phys. Chem. Chem. Phys., 2001, 3, 5274-5282.

21. M. D. Scanlon, J. Strutwolf, A. Blake, D. Iacopino, A. J. Quinn and D. W. M. Arrigan, Anal. Chem., 2010, 82, 6115-6123.

22. S. J. Liu, Q. Li and Y. H. Shao, Chem. Soc. Rev., 2011, 40, 2236-2253.

23. D. W. M. Arrigan, G. Herzog, M. D. Scanlon and J. Strutwolf, in Electroanalytical Chemistry, A Series of Advances, eds. A. J. Bard and C. G. Zoski, 2013, vol. 25, p. to be published.

24. V. Marecek, H. Janchenova, M. P. Colombini and P. Papoff, J. Electroanal. Chem., 1987, 217, 213-219.

25. F. Silva, M. J. Sousa and C. M. Pereira, Electrochim. Acta, 1997, 42, 3095-3103.

26. H. L. T. Ho and R. A. W. Dryfe, Langmuir, 2009, 25, 12757-12765.

27. P. N. Bartlett, Bioelectrochemistry: Fundamentals, Experimental Techniques and Applications, Wiley, Chichester, 2008.

28. E. Palecek, F. Scheller and J. Wang, eds., Electrochemistry of Nucleic Acids and Proteins, Elsevier, Amesterdam, 2005.

29. J. Wang, Chemical Reviews, 2008, 108, 814-825.

30. A. Heller and B. Feldman, Chemical Reviews, 2008, 108, 2482-2505.

31. D. Leech, P. Kavanagh and W. Schuhmann, Electrochim. Acta, 2012, 84, 223-234.

32. C. Pinholt, R. A. Hartvig, N. J. Medlicott and L. Jorgensen, Expert Opinion on Drug Delivery, 2011, 8, 949-964.

33. C. Barbana and M. D. Perez, Int. Dairy J., 2011, 21, 727-741.

34. P. Vanysek and R. P. Buck, J. Electrochem. Soc., 1984, 131, 1792-1796.

35. P. Vanysek, J. D. Reid, M. A. Craven and R. P. Buck, J. Electrochem. Soc., 1984, 131, 1788-1791.

36. P. Vanysek and Z. S. Sun, Bioelectrochemistry and Bioenergetics, 1990, 23, 177-194.

37. S. Amemiya, X. T. Yang and T. L. Wazenegger, J. Am. Chem. Soc., 2003, 125, 1183211833.

38. Y. Yuan, L. Wang and S. Amemiya, Anal. Chem., 2004, 76, 5570-5578.

39. Y. Yuan and S. Amemiya, Anal. Chem., 2004, 76, 6877-6886. 
40. S. C. Ma, V. C. Yang and M. E. Meyerhoff, Anal. Chem., 1992, 64, 694-697.

41. T. Osakai, Y. Yuguchi, E. Gohara and H. Katano, Langmuir, 2010, 26, 11530-11537.

42. A. Trojanek, J. Langmaier, E. Samcova and Z. Samec, J. Electroanal. Chem., 2007, 603, 235-242.

43. A. E. Thomsen, H. Jensen, L. Jorgensen, M. van de Weert and J. Ostergaard, Colloids and Surfaces B-Biointerfaces, 2008, 63, 243-248.

44. F. Kivlehan, Y. H. Lanyon and D. W. M. Arrigan, Langmuir, 2008, 24, 9876-9882.

45. H. A. Santos, V. Garcia-Morales and C. M. Pereira, Chemphyschem, 2010, 11, 28-41.

46. M. A. Mendez, M. Prudent, B. Su and H. H. Girault, Anal. Chem., 2008, 80, 9499-9507.

47. M. A. Mendez, Z. Nazemi, I. Uyanik, Y. Lu and H. H. Girault, Langmuir, 2011, 27, 13918-13924.

48. Z. Samec, Chemical Reviews, 1988, 88, 617-632.

49. D. G. Georganopoulou, D. E. Williams, C. M. Pereira, F. Silva, T. J. Su and J. R. Lu, Langmuir, 2003, 19, 4977-4984.

50. G. Herzog, W. Moujahid, J. Strutwolf and D. W. M. Arrigan, Analyst, 2009, 134, 16081613.

51. H. Jensen, D. J. Fermin, J. E. Moser and H. H. Girault, J. Phys. Chem. B, 2002, 106, 10908-10914.

52. R. A. Hartvig, M. A. Mendez, M. van de Weert, L. Jorgensen, J. Ostergaard, H. H. Girault and H. Jensen, Anal. Chem., 2010, 82, 7699-7705.

53. R. A. Hartvig, M. van de Weert, J. Ostergaard, L. Jorgensen and H. Jensen, Langmuir, 2012, 28, 1804-1815.

54. M. Shinshi, T. Sugihara, T. Osakai and M. Goto, Langmuir, 2006, 22, 5937-5944.

55. M. Shinshi, T. Sugihara, T. Osakai and M. Goto, Langmuir, 2006, 22, 8614-8614.

56. G. Herzog, V. Kam and D. W. M. Arrigan, Electrochim. Acta, 2008, 53, 7204-7209.

57. J. S. Ellis, S. Q. Xu, X. Wang, G. Herzog, D. W. M. Arrigan and M. Thompson, Bioelectrochemistry, 2010, 79, 6-10.

58. M. D. Scanlon, E. Jennings and D. W. M. Arrigan, Phys. Chem. Chem. Phys., 2009, 11, 2272-2280. 
59. A. A. Stewart, Y. Shao, C. M. Pereira and H. H. Girault, J. Electroanal. Chem., 1991, 305, 135-139.

60. M. D. Scanlon, J. Strutwolf and D. W. M. Arrigan, Phys. Chem. Chem. Phys., 2010, 12, 10040-10047.

61. G. Herzog, P. Eichelmann-Daly and D. W. M. Arrigan, Electrochem. Commun., 2010, 12, 335-337.

62. G. Herzog, A. Roger, D. Sheehan and D. W. M. Arrigan, Anal. Chem., 2010, 82, 258264.

63. G. Herzog, M. T. Nolan and D. W. M. Arrigan, Electrochem. Commun., 2011, 13, 723725.

64. S. O'Sullivan and D. W. M. Arrigan, Electrochim. Acta, 2012, 77, 71-76.

65. P. Jing, Y. Kim and S. Amemiya, Langmuir, 2009, 25, 13653-13660.

66. E. Alvarez de Eulate and D. W. M. Arrigan, Anal. Chem., 2012, 84, 2505-2511.

67. E. Alvarez de Eulate, L. Serls and D. M. Arrigan, Analytical and Bioanalytical Chemistry, 2013, 405, 3801-3806.

68. E. Alvarez de Eulate, D. S. Silvester and D. W. M. Arrigan, Chemistry - An Asian Journal, 2012, 7, 2559-2561.

69. D. S. Silvester and D. W. M. Arrigan, Electrochem. Commun., 2011, 13, 477-479.

70. T. Kakiuchi, M. Chiba, N. Sezaki and M. Nakagawa, Electrochem. Commun., 2002, 4, 701-704.

71. Y. Kitazumi and T. Kakiuchi, Bulletin of the Chemical Society of Japan, 2011, 84, 13121320.

72. K. E. Goklen and T. A. Hatton, Biotechnol. Prog., 1985, 1, 69-74.

73. M. J. Pires, M. R. AiresBarros and J. M. S. Cabral, Biotechnol. Prog., 1996, 12, 290-301.

74. M. Y. Vagin, E. V. Malyh, N. I. Larionova and A. A. Karyakin, Electrochem. Commun., 2003, 5, 329-333.

75. M. Y. Vagin, S. A. Trashin, S. Z. Ozkan, G. P. Karpachova and A. A. Karyakin, J. Electroanal. Chem., 2005, 584, 110-116.

76. M. Y. Vagin, S. A. Trashin, G. P. Karpachova, N. L. Klyachko and A. A. Karyakin, J. Electroanal. Chem., 2008, 623, 68-74. 
77. R. Matsui, T. Sakaki and T. Osakai, Electroanalysis, 2012, 24, 1164-1169.

78. S. O’Sullivan and D. W. M. Arrigan, Anal. Chem., 2013, 85, 1389-1394. 